\title{
Z-source Half Bridge Converter with Single LC Network
}

\author{
Kumara Swamy Simhadri \\ Department Of Electrical \& Electronics Engineering \\ Aditya Institute of Technology and Management, Tekkali, Srikakulam, A.P,India \\ Trinadha Burle \\ Department Of Electrical \& Electronics Engineering \\ Aditya Institute of Technology and Management, Tekkali, Srikakulam, A.P,India
}

\begin{abstract}
Thetraditional Z-source converters that are implemented to solve limited voltage problem and the shootthrough problem of a conventional half-bridge converter employ two LC Z-networks. A novel Single phase Z-source half bridge converter is presented as applying a single LC network in the half bridge converter. This Z-source half-bridge converter can solve not only the problems of the shoot-through and limited voltage but also the problem of imbalance at the midpoint voltage of input capacitors. The proposed converter can be effectively utilized for electroplating application.The effectiveness of the proposed converter is verified using MATLAB/Simulink.
\end{abstract}

Keywords-Half-bridge converter, reduced number,shoot-through, Z-source.

\section{INTRODUCTION}

In conventionalhalf-bridge converters the switches are connected in series, as depicted in Fig. 1. This kind of series interconnection of switches may cause shoot-through problem [1]. This kind of inverters also suffer from the problem that ac output voltage is limited below the dc voltage, which is named the limited voltage problem.

To solve the aforementioned problemsan LC network named Z-network [2] isused to couple with the dc source in the converters. The proposed novel source is termed as Z-source. The Z-source converter can be operated in shootthrough mode and its output voltage can reach a wider range than that of the conventional ones.

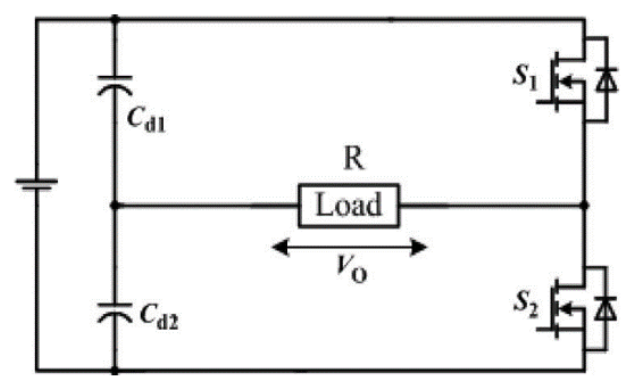

Fig. 1. Conventional half-bridge converter

The Z-source concept proposed in [2] can be applied for half bridge converter. The resulting converter is termed as Z-source half-bridge converter. As seen from Fig. 2 such a converter requires many LC elements, which increase the cost, size, and weight of the converter 


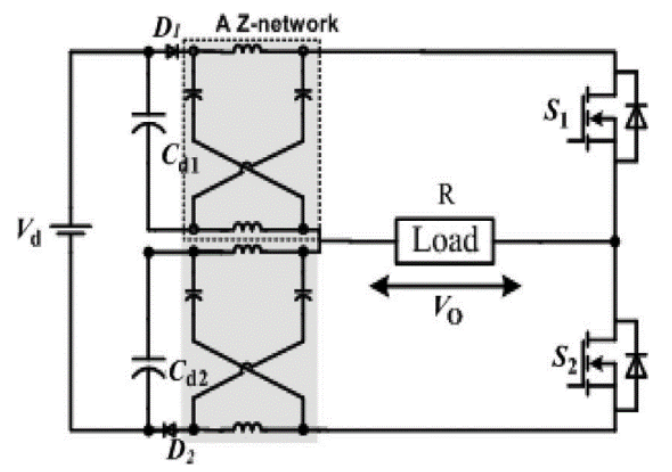

Fig.2. Z-source half-bridge converter with two Z-networks

In [3] a novel Z-source half-bridge converter is proposed, utilizing only a single LC Z-network. This proposed Zsource half-bridge converter not only can solve the limited voltage and the shoot-through problems but also can solve the unbalanced midpoint voltage problem. Furthermore, it can generate a much wider range of output voltages and more abundant waveforms than the conventional Z-source converter making it suitable for electroplating application.

\section{SYSTEM ANALYSIS}

The proposed converter is shown in Fig. 3. The diode D in the circuit prevents current flow to the source. The inductors in the Z-network prevent high current in circuit when the switches are working in shoot-through state.

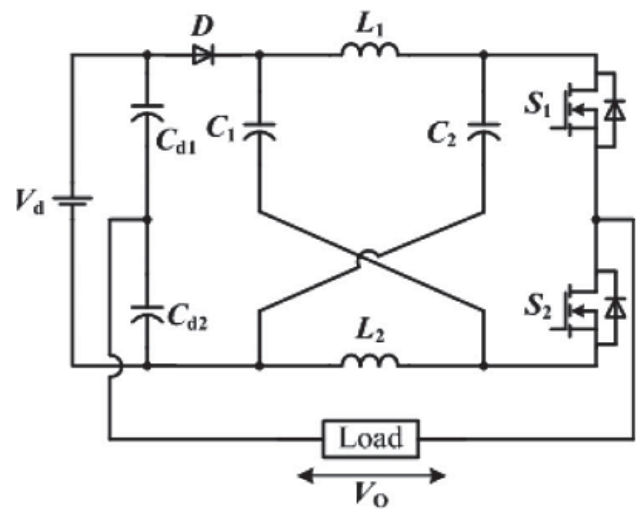

Fig. 3 Z-source half-bridge converter

The following conditions are assumed for simplicity

Entire components in the circuit are ideal

The dead time in the driving pulses is ignored

$\mathrm{C} 1=\mathrm{C} 2$ and $\mathrm{L} 1=\mathrm{L} 2$ in the Z-network

$\mathrm{C} 1, \mathrm{C} 2, \mathrm{Cb} 1$, and $\mathrm{Cb} 2$ has large value

The freewheeling diodes present in the switches are ignored.

Denote the duties of the switches S1 and S2 by D1 and D2, respectively. The proposed converter performs differently in two cases: D1 $+\mathrm{D} 2 \leq 1$ and D1 $+\mathrm{D} 2>1$

A. Case 1: $D 1+D 2 \leq 1$ 
In this case, S1 and S2are switched on at time intervals; then, the circuit is in the non-shoot-through state.

There are three modes corresponding to the states of the switches. In the first mode, when the S1 is on and $\mathrm{S} 2$ is off, in which the current flows out of the source, through the diode, the Z-network, and S1, and then back to the source. In the second mode, when S1 and S2 are off, in which the current also flows out of the source, through the diode and the Z-network, and back to the source; there is no output here. In the third mode, when S2 is on and S1 is off, in which the diode suffers a negative voltage and, thus, turns off. The current flows out of the source, through the load, S2, and the Z-network, and then back to the source. Furthermore, the current direction is also indicated.

B. Case 2: $D 1+D 2>1$

In this case, the behaviour of the switches in the circuit leads to three modes within a switch period $\mathrm{T}$, which correspond to three linear equivalent circuits: Mode 1, when $S_{1}$ and $S_{2}$ are on; Mode 2, when $S_{1}$ is on and $\mathrm{S}_{2}$ is off; and Mode 3, when $\mathrm{S}_{1}$ is off and $\mathrm{S}_{2}$ is on.

\section{THEORITICAL CALCULATIONS}

A. Voltage across midpoint capacitor(Vcd2)

$\mathrm{Vcd} 2$ is calculated and found to be $20 \mathrm{~V}$, based on the relations shown below

$\mathrm{VCd} 2=(2 \mathrm{VC} 2-\mathrm{Vd}) \mathrm{D} 1-\mathrm{VC} 2+\mathrm{Vd}$

B. Output Voltage (V0)

The output voltage is calculated by using the equations below and it is found to be $33 \mathrm{~V}$ for both positive and negative peaks

For positive peak;

$\mathrm{V} 0=\frac{(1-\mathrm{D} 1)}{3-2(\mathrm{D} 1+\mathrm{D} 2)} \mathrm{Vd}$

For negative peak:

$\mathrm{V} 0=-\frac{\mathrm{D}_{1}}{3-2\left(\mathrm{D}_{1}+\mathrm{D}_{2}\right)} \mathrm{Vd}$

C. Capacitor voltage of z-source network (Vc2):

For the capacitor voltage the below mentioned relations are used and the calculated voltage is found to be $53 \mathrm{~V}$.

$V o=V c 2-V c d 2$

$V c 2=V 0+V c d 2$

D. Output power and efficiency:

The output power and efficiency of the converter are calculated by the following relations.

$$
\begin{aligned}
P o & =\frac{D 1 V p^{2}+(1-D 1) V n^{2}}{R} \\
P \text { in } & =\text { VdIav } \\
\eta \% & =\frac{\text { Pout }}{\text { Pin }} \times 100
\end{aligned}
$$

The calculated output power and efficiency are $108.9 \mathrm{~W}$ and $85.71 \%$ respectively. 


\section{SIMULATION AND RESULTS}

The proposed converter is simulated in MATLAB/Simulink environment and the simulink diagram is shown in Fig. 4. The parameters used for simulation are listed in Table 1.

Table 1. List of parameters used for simulation

\begin{tabular}{|l|l|}
\hline Parameter & Value \\
\hline Vin & $40 \mathrm{v}$ \\
\hline Vo & $33 \mathrm{v}$ \\
\hline Cd1, Cd2 & $470 \mu \mathrm{F}$ \\
\hline C1, C2 & $470 \mu \mathrm{F}$ \\
\hline L1, L2 & $100 \mu \mathrm{H}$ \\
\hline R & $10 \Omega$ \\
\hline T & $20 \mu \mathrm{s}$. \\
\hline
\end{tabular}

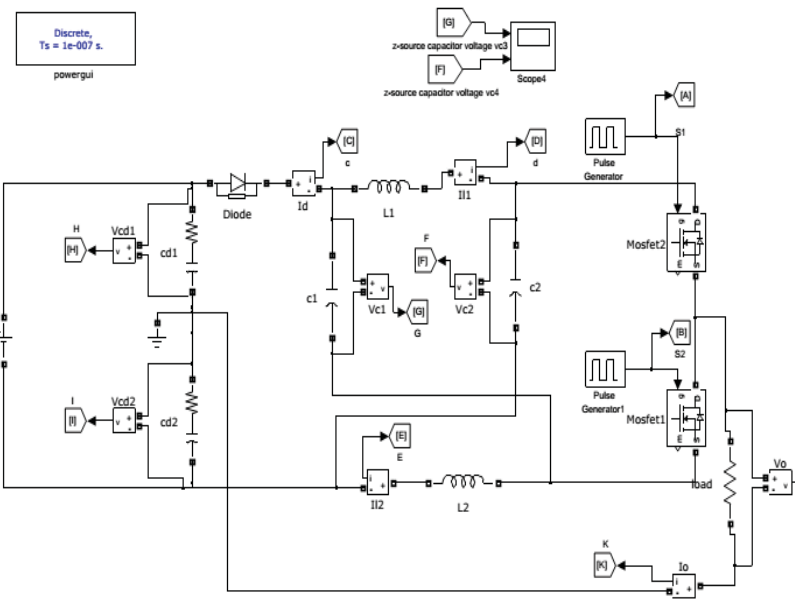

Fig. 4 MATLAB/Simulink diagram of Z-source half bridge converter

The output voltage and current waveforms are depicted in Fig.5 and Fig.6 respectively. The peak to peak current is $6.54 \mathrm{~A}$ and the output voltage is $32.7 \mathrm{~V}$. The voltage across $\mathrm{Cb} 1$ and $\mathrm{Cb} 2$ are $\mathrm{Vcb} 1=\mathrm{Vcb} 2=20 \mathrm{~V}$. So midpoint voltages are balanced. 


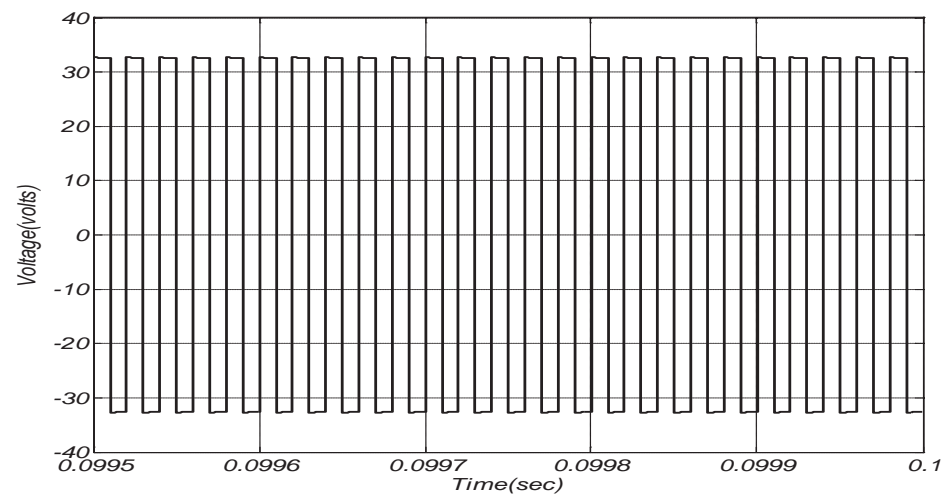

Fig. 5 Output voltage

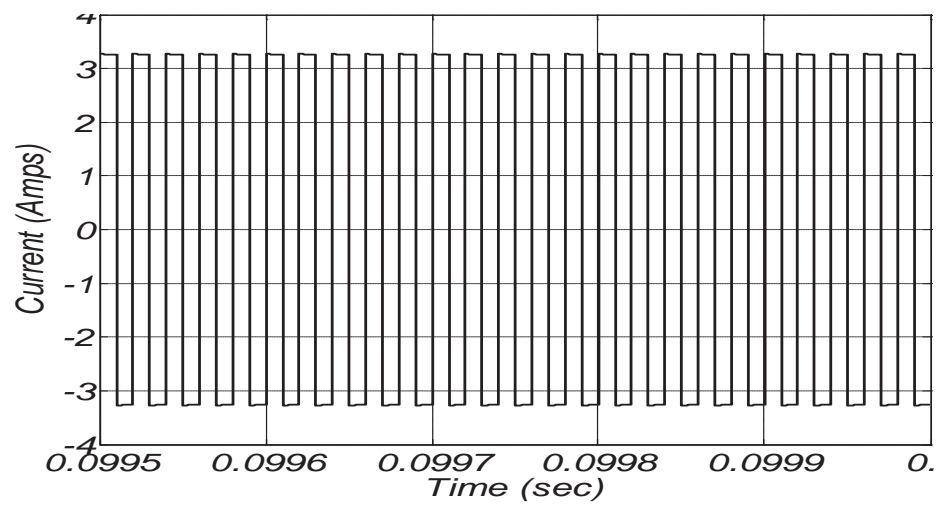

Fig. 6 Output current

\section{CONCLUSION}

The Z-source half bridge converter discussed so far is capable of addressing the limited voltage and shoot-through problems faced by conventional half-bridge converters. Furthermore the proposed converter utilizes less number of LC components unlike the traditional Z-source half-bridge converters. The effectiveness of the converter is verified through simulations in MATLAB/Simulink

\section{REFERENCES}

[1] B. Zhao, Q. G. Yu, Z. W. Leng, and X. Y. Chen, "Switched Z-source isolated bidirectional DC-DC converter and its phase-shifting shootthrough bivariate coordinated control strategy," IEEE Trans. Ind. Electron., vol. 59, no. 12, pp. 4657-4670, Dec. 2012.

[2] F. Z. Peng, "Z-source inverter," IEEE Trans. Ind. Appl., vol. 39, no. 2, pp. 504-510, Mar./Apr. 2003.

[3] Guidong Zhang, ZhongLi, Bo Zhang, DongyuanQiu, Wenxun Xiao, and Wolfgang A. Halang "A Z-Source Half-Bridge Converter" IEEE Trans. Ind. Electron., vol. 61, no.3, pp. 1269-1279, March 2014. 